\title{
Best Article Award: Fleissig
}

\author{
Katherine S. Virgo ${ }^{1}$
}

Published online: 14 February 2018

(C) International Atlantic Economic Society 2018

The Atlantic Economic Journal is proud to announce that the winner of the 2017 Best Article Award is Adrian Fleissig, Mihaylo College of Business and Economics, California State University at Fullerton. His paper entitled, "Changing Trends in U.S. Alcohol Demand," appeared in the September 2016 issue of the AEJ. The AEJ Best Article Award committee reviewed all eligible papers (those with ratings of top $25 \%$ or better) published in 2016. The committee was chaired by IAES Vice President, Ann Harrison, William H. Wurster Professor of Multinational Management and Professor of Business Economics and Public Policy, Wharton School, University of Pennsylvania. Members of the committee included the AEJ Board of Editors and IAES Endowment Fund sponsors. The Managing Editor gratefully acknowledges the participation and diligence of all committee members who participated in the review process. The award emphasizes the intellectual and scholarly approach to economic research which has always been a focal point of the AEJ. A brief summary of the award-winning paper follows.

According to Fleissig's review of the literature, many studies have estimated elasticities with respect to consumption of various types of alcohol. Such studies typically do not separate out the impact on alcohol demand by the type of alcohol causing the change in relative prices. Also absent from this literature is research identifying an optimal measure of substitution or global substitution estimates that allow for variation over time. Using data from the Euromonitor Global Market Information Database for 1991-2012, the author calculated estimates of the elasticities of substitution for alcohol over time using a system of equations derived from a globally functional form, specifically the Fournier flexible form. Own-price, cross-price and Morishima elasticities of substitution were calculated. The study's purpose was to determine how substitution changes over time and during recessions for spirits, wine and beer, and to evaluate the specific alcohol type that causes relative changes in prices.

Katherine S. Virgo

kvirgo@emory.edu

1 Emory University, Atlanta, GA 30322, USA 
Such information is key to understanding how consumers might react to policy aimed to curb the negative effects of alcohol consumption.

The results indicated that elasticities of substitution for beer, wine, and spirits did indeed vary over time, particularly during the 1991-1992 recession. Own-price elasticities indicated that alcohol demand was inelastic over time. In general, cross-price elasticities between beer and wine were elastic. Some asymmetric substitution was detected for beer with either wine or spirits. This finding suggests that alcohol expenditure may be dependent on the specific product undergoing a price change. This is typically not true for spirits and wine.

The demand for beer was the most inelastic, consistent with the literature. While the demand for wine and spirits was also inelastic, demand for wine and spirits was more elastic when compared to demand for beer. Wine and spirits can be considered luxuries in consumption since estimated expenditure elasticities exceed unity for beer. Wine had the largest estimated income elasticities of demand in the sample. According to Fleissig, estimates of income elasticities of demand vary widely in the literature. Some studies provide evidence that wine, beer, or spirits can be necessities in consumption.

Though the magnitudes differed, the Morishima elasticities of substitution revealed similar trends to the cross-price elasticities. A unique aspect of the Morishima elasticity estimates was detected by Fleissig. Consumer choices among alcohol types vary by the factor causing the change in the relative price of beer, wine, and spirits. For example, when choosing between beer and wine, in response to an increase in the price of beer, consumers switch from beer to wine. In contrast, when the price of spirits changes, consumer preferences between spirits and wine change by relatively little.

Further research is needed. However, the take home message of the Fleissig study is that policy aimed at reducing the social costs of excessive drinking must consider how consumer preferences for alcohol change over time, during recessions, and which type of alcohol causes relative changes in prices. 